\title{
Intestinal Intramural Vascular Anastomoses
}

\author{
Raimondo M. Cervellione, Gabriella Varga, Daniel Hajnal, Daniel Erces, Jozsef \\ Kaszaki, Rachel Harwood, George Rakoczy \& Tamas Cserni
}

To cite this article: Raimondo M. Cervellione, Gabriella Varga, Daniel Hajnal, Daniel Erces, Jozsef Kaszaki, Rachel Harwood, George Rakoczy \& Tamas Cserni (2016) Intestinal Intramural Vascular Anastomoses, Journal of Investigative Surgery, 29:1, 51-56, DOI: $\underline{10.3109 / 08941939.2015 .1045106}$

To link to this article: http://dx.doi.org/10.3109/08941939.2015.1045106

曲 Published online: 14 Sep 2015.

Submit your article to this journal $\pi$

Џ Article views: 25

Q View related articles $\sqsubset$

View Crossmark data ¿ 


\title{
ORIGINAL ARTICLE
}

\section{Intestinal Intramural Vascular Anastomoses}

\author{
Raimondo M. Cervellione, ${ }^{1,2}$ Gabriella Varga, ${ }^{2}$ Daniel Hajnal, ${ }^{2}$ Daniel Erces, ${ }^{2}$ \\ Jozsef Kaszaki, ${ }^{2}$ Rachel Harwood, ${ }^{3}$ George Rakoczy, ${ }^{3}$ Tamas Cserni ${ }^{1,2}$ \\ ${ }^{1}$ Department of Paediatric Urology, Royal Manchester Children's University Hospital, Manchester, United Kingdom \\ ${ }^{2}$ Institute of Surgical Research, University of Szeged, Szeged, Hungary ${ }^{3}$ Department of Paediatric Surgery, Royal \\ Manchester Children's University Hospital, Manchester, United Kingdom
}

\begin{abstract}
Introduction: Present surgical techniques are rarely relying on intestinal intramural vascular anastomoses; however, this could open new limits in reconstructive surgery. Our aim was to study the efficacy of the antimesenteric and the longitudinal intramural vascular anastomoses in a porcine model. Material and Methods: Five minipigs were used. Antimesenteric anastomoses: jejunal loops were detubularized by cutting along the antimesenteric line (Control), in the middle between the mesenteric and antimesenteric border (Group 1) and close to the mesenteric line (Group 2). Mucosal microcirculation (red blood cell velocity, perfusion rate) was recorded with orthogonal polarization spectral imaging (Cytoscan A/R) at the long edge of the detubularized bowel. Longitudinal anastomoses: records were made on a continuous jejunal loop following antimesenteric incision, detubularization, and subsequent ligation of 2, 4, and 6 neighboring vasa recta in the middle of the loop. The same study was repeated on the free end of completely divided jejunal segments with ligation of 2, 4, or 6 vasa recta. Results: Antimesenteric anastomoses: There was no statistically significant difference in red blood cell velocity and perfusion rate between Control and Groups 1 and 2. Longitudinal anastomoses: The red blood cell velocity dropped significantly, while the perfusion rate did not change significantly after ligation of 4 vasa recta in the continuous loop. In the loop with a free end, however, both parameters decreased significantly after ligation of four vessels. Conclusion: It is safe to rely on antimesenteric intramural anastomoses but strong limitation of longitudinal intramural vascular anastomoses should be considered in intestinal reconstructions.
\end{abstract}

Keywords: intestine; intramural blood supply; orthogonal spectral imaging; pig

\section{INTRODUCTION}

According to the present knowledge, the blood supply of the bowel is segmental and the mesenteric vessels divide into terminal arteries called vasa recta (VR) before they reach the intestine. The VR encircle and supply both halves of the intestine remaining perpendicular to the long axis of the bowel [1].

Thus, during intestinal reconstructions, surgeons rarely rely on the intestinal intramural circulation and as a general rule no bowel segment without mesentery directly attached should be used for reconstruction. When detubularization of the bowel is performed, it is done mainly along the antimesenteric line, except in a modified Monti [2] procedure (catheterizable channel for augmented bladder) and in a recently developed technique by our team, in the Spiral Intesti- nal Lengthening and Tailoring (SILT) for short bowel syndrome [3].

However, if there were direct convincing evidence for effective intramural communications between anterior and posterior branches of the VR (antimesenteric intramural vascular anastomoses) and the neighbouring VR (longitudinal intramural vascular anastomoses), the surgeon would feel more safer to rely on intramural circulation. This could open new limits in designing new type of reconstructions (stomas, anastomoses, bladder augmentation, catheterizable channels, etc.)

Anastomosists hypothesized intramural communication may exist between the opposing and the neighboring VR (antimesenteric and longitudinal intramural vascular anastomoses) [4-8] but the efficacy of these connections have never been measured. However, re- 
search on intestinal microcirculation and wound healing is very popular nowadays $[9,10]$

The OPS technique is an accepted method of demonstrating microcirculation in vivo [11]. The velocity of the circulating RBCs, and the perfusion rate which can be accurately measured, are sensitive markers of the microcirculation. Pigs share similar anatomic and physiologic characteristics with humans involving the cardiovascular, urinary, and digestive systems and they have been increasingly used for translational research, surgical models, and procedural training [12-14].

Our aim was to examine the efficacy of the longitudinal and antimesenteric intramural intestinal vascular anastomoses using intravital videomicroscopy in a porcine model.

\section{MATERIAL AND METHODS}

The experiment was approved by the Committee of Animal Research at the University of Szeged (Permission no: I-74-14/2012 MÁB).The study was performed on five anesthetized Vietnamese mini pigs $(n=5$, weight: $25-30 \mathrm{~kg}$ ). The animals were kept under conventional circumstances, in standard cages, were fed with commercially available mixed food, were fasted $36 \mathrm{hr}$ before surgery, and had always free access to water. Anesthesia was induced with an intramuscular injection of a mixture of ketamine $(20 \mathrm{mg} / \mathrm{kg})$ and xylazine $(2 \mathrm{mg} / \mathrm{kg}$ ) and maintained with a continuous infusion of propofol ( $2 \% ; 50 \mu \mathrm{l} / \mathrm{kg} / \mathrm{min}$ i.v.). Endotracheal tube was inserted and the animals were ventilated mechanically with volume-controlled ventilator. The tidal volume was set at $8-9 \mathrm{ml} / \mathrm{kg}$, and the respiratory rate was adjusted to maintain the endtidal carbon dioxide pressure between 35 and $45 \mathrm{mmHg}$. Norocarp S (carprofen; $4 \mathrm{mg} / \mathrm{kg}$ ) and normal saline infusion were administered via canulated ear vein. Hearth rate, $\mathrm{O}_{2}$ saturation, $\mathrm{pCO}_{2}$, and body temperature were continuously monitored by capnometry.

Examination of Antimesentric Intramural Vascular Anastomoses: Ten-cm-long jejunal loops were isolated in anesthetized pigs $(n=5)$. Control Group: After antimesenteric incision, the bowel loop was opened and the mucosal microcirculation has been recorded with orthogonal polarization spectral (OPS) imaging technique at the antimesenteric edges of the opened bowel strip. In Group 1, a longitudinal incision was performed on the bowel loop between the mesenteric and antimesenteric border in the middle. After detubularization, the microcirculation has been recorded at the edge of the opened bowel strip beyond the antimesenteric line. In Group 2, the loops were cut next to the mesenteric line. After detubularization, the microcirculation has been recorded at the edge of the opened bowel strip beyond the antimesenteric line (Figure 1).

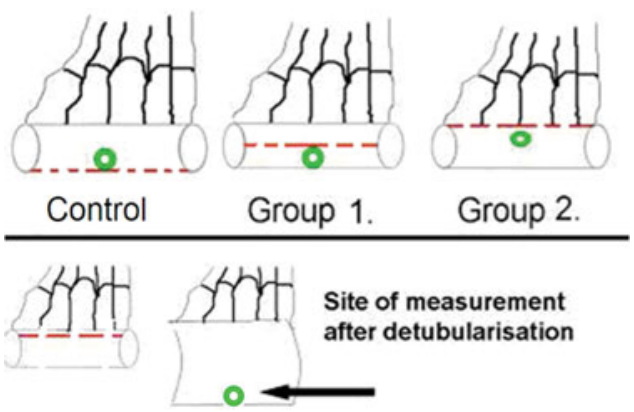

FIGURE 1 Examination of antimesentric anastomoses: Group 1: Control group, the loop was cut at the antimesenteric line, Group 2: Bowel cut between the mesenteric and antimesenteric edge, Group 3: Bowel cut at the mesenteric site. The circle shows the sites of OPS measurements, the line represents the cut on the bowel segment.

Examination of Longitudinal Intramural Vascular Anastomoses: Mucosal microcirculation was recorded on a continuous jejunum after antimesenteric incision. Ligation of 2, 4, and 6 neighbouring vasa recta was performed sequentially and the microcirculation was recorded on the bowel at the midpoint of these vessels. There was some irregularity of vessels in the mesentery of the pigs. Maximum two vessels running next to each other were considered as vasa recta. The same study was done on a jejunum segment with free end starting the ligation from the free end of the bowel loop and measuring the microcirculation at the free end (Figure 2).

The intravital OPS imaging technique (Cytoscan A/R, Cytometrics, PA, USA) was used for visualization of the microcirculation of the mucosa. The microscopic images were recorded with an S-VHS video recorder (Panasonic AG-TL 700). Microcirculatory evaluation was performed offline by frame-to-frame analysis of the videotaped images. The capillary red blood cell (RBC) velocity $\left(\mu \mathrm{m} \mathrm{s}^{-1}\right)$ changes were determined and capillary perfusion rate (CPR) were calculated from the ratio of perfused capillary and total capillary length in the intestinal villi in three separate fields by means of a computer-assisted image analysis system (IVM Pictron, Budapest, Hungary).

The data analysis was performed with a statistical software package (SigmaStat for Windows; Jandel Scientific, Erkrath, Germany). The distribution of our experimental data was analyzed by the Kolmogorov-Smirnov normality test. Failure of the normality test indicated nonparametric distribution of the data. Accordingly, we employed nonparametric statistical tests. Differences between groups were analyzed with Kruskal-Wallis one-way analysis of variance on ranks, followed by Dunn's method for pairwise multiple comparison. In the Figures, median values 

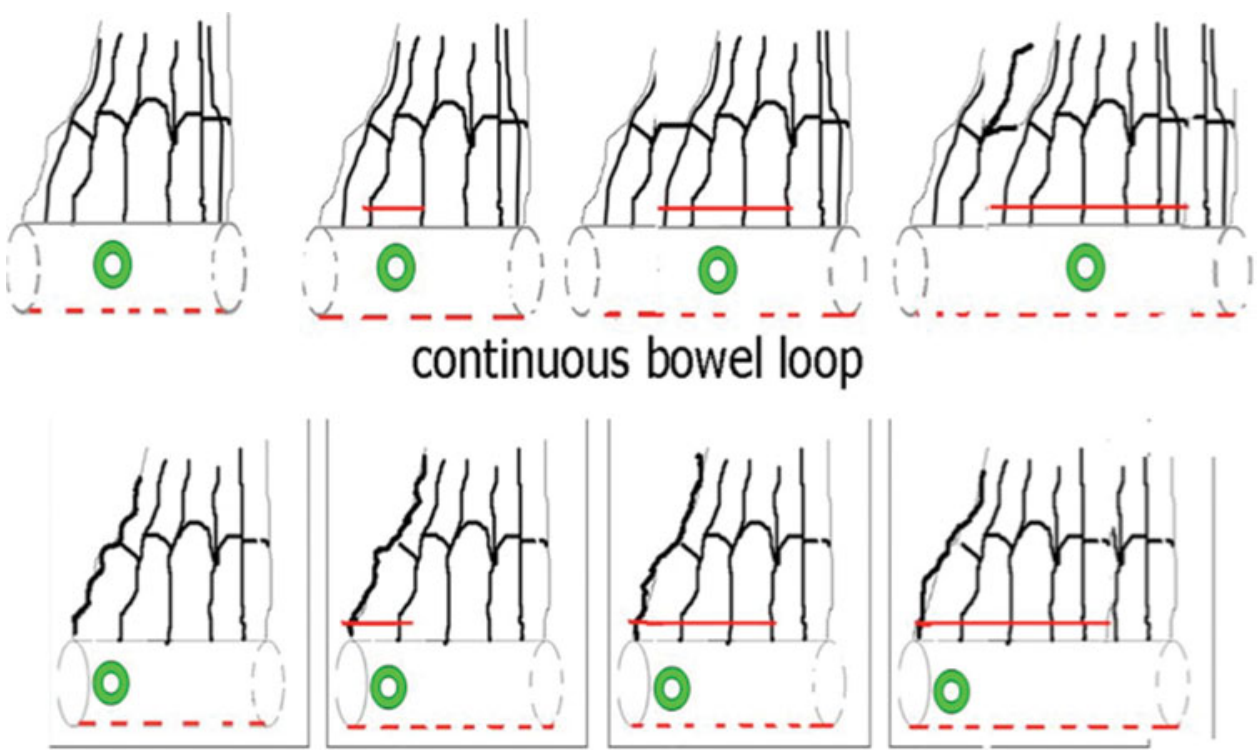

\section{loop with a free end}

FIGURE 2 Examination of longitudinal anastomoses: Mucosal microcirculation was recorded on in continuity jejunum and end loop after antimesenteric incision and ligation of 2, 4, and 6 neighboring vasa recta. The same experiment was repeated on a loop with a free end, starting the ligations from the free end. The circles are marking the site of measurements. All the loops were cut at the antimesenteric line.

and 75th and 25th percentiles are given; $p$ values $<0.05$ were considered significant.

\section{RESULTS}

Examination of Antimesenteric Intramural Vascular Anastomoses: There was no significant difference in RBC velocity and the perfusion rate at the site of measurements between the Control Group and Groups 1-2.

\section{Examination of Longitudinal Intramural Vascular Anastomoses}

Continuous loop: No significant changes in the RBC velocity and perfusion rate have been seen after ligation of 2 vasa recta. However the RBC velocity dropped significantly after ligation of 4 vasa recta, but the change in the perfusion rate remained nonsignificant. After ligation of 6 vasa recta, both parameters approached the 0 level.

Loop with the free end: No significant changes in the $R B C$ velocity and perfusion rate have been seen after ligation of 2 vasa recta. The RBC velocity diminished significantly after ligation of 4 vasa recta in a similar manner to the continuous loop. The reduction in perfusion rate was more expressed and significant too. After ligation of 6 vasa recta, both parameters approached the 0 level.

Data are summarized in Tables 1 and 2 and Figures 3 and 4 .
TABLE 1. The RBC velocity and perfusion rate in different groups did not show significant differences

\begin{tabular}{cccc}
\hline & Control & Group 1 & Group 2 \\
\hline RBCV & Median: 443,300 & Median: 421,000 & Median: 417,150 \\
$\mu \mathrm{m} / \mathrm{s}$ & & & \\
& $25 \%: 362,500$ & $25 \%: 355,750$ & $25 \%: 397,600$ \\
& $75 \%: 472,725$ & $75 \%: 456,000$ & $75 \%: 490,300$ \\
PR \% & Median: 0,783 & Median: 0,661 & Median: 0,674 \\
& $25 \%: 0,768$ & $25 \%: 0,608$ & $25 \%: 0,652$ \\
& $75 \%: 0,840$ & $75 \%: 0,809$ & $75 \%: 0,730$ \\
\hline
\end{tabular}

Evidence of antimesenteric anastomoses of vasa recta.

\section{DISCUSSION}

Anastomosists have extensively studied intestinal circulation in the past, but several controversies have been left unanswered. According to Jonnesco (1912), the vasa recta of the bowel divide into two equal branches, which encircle the gut to anastomose with each other at the antimesenteric border [4]. Eisberg [5] and Noer [6] claimed that there are numerous anastomoses between the smaller branches of adjacent vasa recta in the bowel wall. Cokkinis [7] observed that the intramural vessels ramify in an arborescent manner, but he found no evidence for anastomoses of the contiguous vessels. It has been reported that the subperitoneal ramification stops short a little distance from the antimesenteric border and a clear longitudinal band free from visible vessels is present in all specimens [5-7]. Doran studying the upper jejunum in human 
TABLE 2. RBC velocity dropped significantly* $(p>0.05)$ after ligation of 4 vasa recta, the perfusion rate was significantly lower after ligation of four vessels on the free ending loop while it remained similar on the continuous loop

\begin{tabular}{|c|c|c|c|c|c|}
\hline Number of ligated vessels & & 0 & 2 & 4 & 6 \\
\hline \multirow[t]{6}{*}{ Continous bowel loop } & \multirow[t]{3}{*}{$\mathrm{RBCV} \mu \mathrm{m} / \mathrm{s}$} & Median: 443,300 & Median: 416,000 & Median: $229,500 *$ & Median: $10,000 *$ \\
\hline & & $25 \%: 362,500$ & $25 \%: 379,100$ & $25 \%: 200,000$ & $25 \%: 3,750$ \\
\hline & & $75 \%: 472,725$ & $75 \%: 472,725$ & $75 \%: 278,000$ & $75 \%: 16,250$ \\
\hline & \multirow[t]{3}{*}{ PR \% } & Median: 0,783 & Median: 0,717 & Median: 0,674 & Median: 0,0100 * \\
\hline & & $25 \%: 0,768$ & $25 \%: 0,678$ & $25 \%: 0,534$ & 25\%: 0,000 \\
\hline & & $75 \%: 0,840$ & $75 \%: 0,779$ & $75 \%: 0,741$ & $75 \%: 0,0187$ \\
\hline \multirow[t]{6}{*}{ Loop with a free end } & \multirow[t]{3}{*}{$\mathrm{RBCV} \mu \mathrm{m} / \mathrm{s}$} & Median: 443,300 & Median: 365,000 & Median: $132,000 *$ & Median: $10,000 *$ \\
\hline & & $25 \%: 362,500$ & 25\%: 355,400 & $25 \%: 104,500$ & $25 \%: 2,500$ \\
\hline & & $75 \%: 472,725$ & $75 \%: 388,750$ & $75 \%: 174,000$ & $75 \%: 17,500$ \\
\hline & \multirow[t]{3}{*}{$\mathrm{PR} \%$} & Median: 0,783 & Median: 0,640 & Median: 0,530* & Median: $0,000 *$ \\
\hline & & 25\%: 0,768 & $25 \%: 0,637$ & $25 \%: 0,326$ & 25\%: 0,000 \\
\hline & & $75 \%: 0,840$ & $75 \%: 0,662$ & $75 \%: 0,587$ & $75 \%: 0,0175$ \\
\hline
\end{tabular}

Evidence of longitudinal anastomoses of vasa recta.

postmortem specimens found communications only of the arteries of the caliber of the primary branches of the vasa recta. Neither the smaller arteries, nor of those arising from the sides of the larger vessels showed communications. The position of these anastomoses was found irregular and not conforming to any set pattern [8].

In our study, we demonstrated undisturbed microcirculation far beyond the antimesenteric line right up to the mesenteric line in a bowel segment, which was detubularized next to the mesentery. In clinical practice, it means that at detubularization, the surgeon does not need to follow the antimesenteric line, it can be done anywhere else along the circumference safely without compromising microcirculation. This is in accordance with our experience with the SILT technique that we recently developed. In this procedure, the intestine is incised along a spiral line. This technique proved viable in animal models and in clinical practice $[15,16]$.
In clinical practice, paramesenteric detubularization was only previously used in a modified Monti procedure before, to create a catheterizable channel for augmented bladder [2]. The aim of the paramesenteric detubularization was to leave sufficient length mesentery free end of the channel to allow easy implantation in the bladder in an antireflux manner to achieve continence. There were no major concerns reported regarding viability of these channels; however, these channels only serve for regular catheterization and anastomosis insufficiency, anastomotic leak, atrophy, or minor scar formation is not a major concern.

Urologists have made several attempts to create a reliable, but "mucus-free" bladder augmentation, but this still remains unsolved. In an experimental animal study, "mucus-free" bladder augmentation has been peformed with paramesenterically detubularized reverse seromuscular bowel flaps. All the flaps fibrotized and contracted within a few weeks [17]. It was not clear whether the paramesenteric detubularization or

\section{RBC velocity $(\mu \mathrm{m} / \mathrm{sec})$}

\section{Perfusion rate $(\%)$}
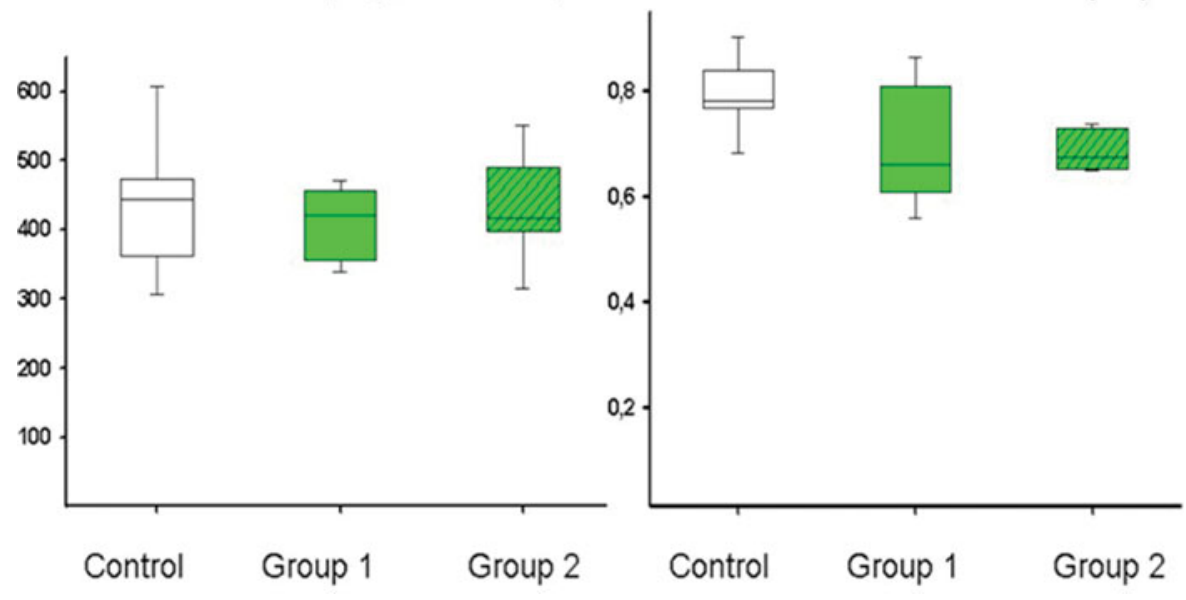

FIGURE 3 Evidence of antimesenteric anastomoses of vasa recta. The RBC velocity (left) and perfusion rate (right) measured by OPS in different groups did not show significant $(p>$ $0,05)$ differences. 

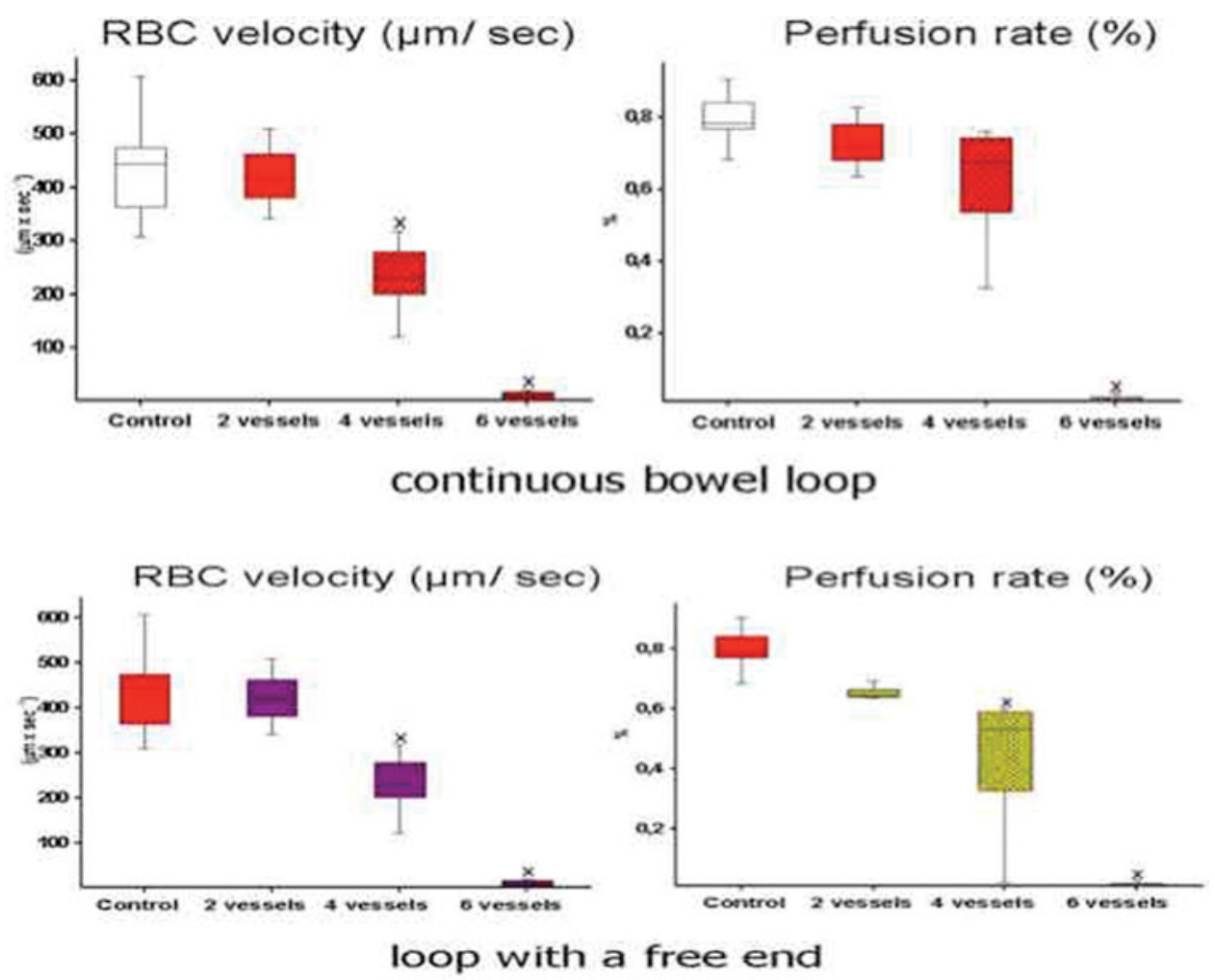

FIGURE 4 Evidence of longitudinal anastomoses of vasa recta. RBC velocity (left) dropped significantly after ligation of 4 vasa recta, the perfusion rate was significantly lower after ligation of four vessels on the free ending loop while it remained similar on the continuous loop.

the mucosectomy was responsible and the technique was abandoned. It is now clear the paramesenteric detubularization cannot be claimed to be the reason for this. Our team was able to perform successful bladder augmentation with paramesenterically detubularized flaps in experimental settings without mucosectomy [18]. We are now focusing on less traumatic mucosectomy and are getting closer to achieve "mucus-free" augmentation.

Detubularization of the ileum next to the mesentery rather than at the antimesenteric line may allow us to create longer reaching vascularised ileal flaps for bladder augmentation during clam ileocystoplasty, which is particularly useful if the mesentery is short. This could be also useful for vaginal replacement in cloacal anomalies when the bowel segment needs to reach to the perineum.

To examine the efficacy of the longitudinal anastomoses, the antimesenteric anastomoses were cut. The bowel wall received perfusion only through the neighbouring longitudinal anastomoses at the site of the measurements after the corresponding vasa recta had been cut. On the continuous loop, the blood supply came from both sides, while on the loop with the free end, only from one side.

The fact that ligation of a 2 vasa recta has not affected the microcirculation is a clear evidence of the presence of functioning longitudinal intramural anastomoses. The efficacy of these anastomoses was limited up to ligation of four vessels. We expected the loop with the free end to be more sensitive to vasa recta ligation having anastomoses only from one side. However, we did not find a marked difference between the two loops. The reduction of the RBC velocity was very similar, only the perfusion rate has dropped more rapidly in the loop with the free end. These findings are not really surprising and justify the present surgical practice that only a very short bowel segment detached from mesentery can be used safely.

In conclusion, in this study, we provided direct evidence for safe and reliable antimesenteric intestinal intramural anastomoses which will open new oppotunities in reconstructive surgery. However, the strong limitation of longitudinal intramural vascular anastomoses should be considered in these opportunities.

Declaration of interest: The authors report no conflicts of interest. The authors alone are responsible for the content and writing of the article. The authors report no proprietary or commercial interest in any product mentioned or concept discussed in this article. The experiment was approved by the Committee of Animal Research at the University Szeged (Permission no: I-74-14/2012 MA'B). 


\section{REFERENCES}

1. Michelis NA, et al. Intestinal vascularization. J Int College of Surg. 1963; 39:127-170.

2. Monti PR, Lara RC, Dutra MA, et al. New techniques for construction of efferent conduits based on the Mitrofanoff principle. Urology 1997;49:112-115.

3. Cserni T, Takayasu H, Muzsnay Z, et al. New idea of intestinal lengthening and tailoring. Pediatr Surg Int. 2011;27:1009-1013.

4. Jonnesco T, Soulik A. In: Poirier and Charpy's Traitg d'Anatomie Hurmaine, Vol. iv, Pt. i, 3rd ed. Paris: Masson et Cie; 1912.

5. Eisberg HB. Intestinal arteries. Anat Rec. 1924;28:227-242.

6. Noer RJ. The blood vessels of the jejunum and ileum: A comparative study of man and certain laboratory animals. Amer J Anat. 1943;73:293-334.

7. Cokkinis AJ. Observations on the mesenteric circulation. J Anat. 1930;64:200-205.

8. Doran FS. Intramural blood supply of the upper jejunum in man. J Anat. 1950;84:283-286.

9. Grommes J, Binnebösel M, Klink CD, et al. Comparison of intestinal microcirculation and wound healing in a rat model. J Invest Surg. 2013;26:46-52.

10. Turóczi Z, Fülöp A, Czigány $Z$, et al. Improvement of small intestinal microcirculation by postcondition- ing after lower limb ischemia. Microvasc Res. 2015;98C: 119-125.

11. Cerný V, Turek Z, Parízková R. Orthogonal polarization spectral imaging. Physiol Res. 2007;56:141-147.

12. Swindle MM, Makin A, Herron A, et al. Swine as Models in Biomedical Research and Toxicology Testing. Vet Pathol. 2012;49:344-356.

13. Swindle MM. Swine as Models in Biomedical Research. Ames, IA: Iowa State University Press; 1992.

14. Hoeppner J, Crnogorac V, Hopt UT, et al. The pig as an experimental model for colonic healing study of leakage and ischemia in colonic anastomosis. J Invest Surg. 2009;22:281-285.

15. Cserni T, Varga G, Erces D, et al. Spiral intestinal lengthening and tailoring- first in vivo study. J Pediatr Surg. 2013;48:1907-1913.

16. Cserni T, Biszku B, Guthy I, et al. The first clinical application of the spiral intestinal lengthening and tailoring (Silt) in extreme short bowel syndrome. J Gastrointest Surg. 2014;18:1852-1857.

17. Cheng E, Rento R, Grayhack J, et al. Reversed seromuscular flaps in the urinary tract in dogs. J Urol. 1994;152: 2252-2257

18. Cserni T, Cervellione RM, Hajnal D, et al. Alternative ileal flap for bladder augmentation if mesentery is short. J Ped Urol. 2015;11:64.e1-6. 